\title{
Demographic trends and climate over 35 years in the Barro Colorado 50 ha plot
}

\author{
Richard Condit ${ }^{1,4^{*}}$ (D), Rolando Pérez² ${ }^{2}$ Suzanne Lao², Salomón Aguilar² and Stephen P. Hubbell ${ }^{3}$
}

\begin{abstract}
Background: The first three censuses of the 50-ha plot at Barro Colorado Island spanned an unusually harsh dry season during the 1983 El Niño. By the early 1990s, we had documented increases in tree mortality, tree growth, and large population fluctuations of many species during the 1982-1985 census interval. At the time, we asserted that increasing drought frequency would greatly affect the forest. With the benefit of five more censuses at Barro Colorado from 1995-2015, we can now put the 1980 conditions in a longer perspective and test the hypothesis that increasing droughtiness has continued to change the forest.
\end{abstract}

Methods: A 50-ha forest plot on Barro Colorado Island was censused eight times, in 1982 and every five years since 1985. All free-standing woody stems were measured, mapped, and identified in each census.

Results: 1) The period 1982-1992 included several extreme dry seasons, not just 1983, but since then there have been few such droughts.

2) Dbh growth declined from a peak in the early 1980s to its lowest in the early 1990s. From 1995-2015 it increased slightly, but not returning to the initial peak. Nearly every species and all dbh categories followed the same pattern. 3) The elevated stand-wide mortality rate of large trees during the 1982-1985 drought has not returned, and most individual species showed the same pattern of elevated mortality in the 1980s followed by low and fairly stable mortality after 1990.

4) Sapling mortality declined after 1985, but rose again in the late-90s, so the 1980 s drought period no longer looks unusual. Mortality of individual species' saplings fluctuated erratically, including cases where mortality during the drought was lower than after.

5) Population sizes of individual species fluctuated in all possible directions. Some species declined precipitously during the drought, then recovered, but others did not recover. Other species increased in abundance during the drought.

Conclusions: Droughts of the 1980s elevated tree growth and mortality at Barro Colorado, but since 1990, demographic rates have remained lower, paralleling a moderate climate with few severe droughts after 1990. Moisture-demanding species suffered during the drought, but many have since recovered. We do not know how often such drought periods recur. Moreover, many species' abundances fluctuated over 35 years with no known cause.

\section{Background}

Forests change at many time scales. Tree ring records of the past century show peaks in growth rate lasting anywhere from one year up to 10-20 years (Briffa et al. 1992; Brienen and Zuidema 2005; van der MaatenTheunissen et al. 2016). Few tropical records exist, but Enquist and Leffler (2001) attributed 15-25 year tree-ring

\footnotetext{
*Correspondence: conditr@gmail.com

${ }^{1}$ Field Museum of Natural History, 1400 S. Lake Shore Dr., Chicago, IL 60605, USA

${ }^{4}$ Morton Arboretum, 4100 Illinois Rte. 53, Lisle, IL 60532, USA

Full list of author information is available at the end of the article
}

periods to oceanic regimes, and a number of studies document annual fluctuations with rainfall (Devall et al. 1995; Brienen and Zuidema 2005; Couralet et al. 2010). Because tree-ring records lasting decades overlap with the time-scale of the longest-running tree plots, we anticipate that plot censuses will capture increases or decreases in growth, or both (Nath et al. 2006; Seydack et al. 2011). On top of growth, plots offer mortality records, not observable from tree ring chronologies, and there is ample evidence about decadal climatic effects on tree mortality, especially drought but also temperature (Clark and 
Clark 1994; Nakagawa et al. 2000; Williamson et al. 2000; Newbery and Lingenfelder 2009; Allen et al. 2010; Enquist and Enquist 2011; Seydack et al. 2011; Greenwood et al. 2017; O'Brien et al. 2017).

At Barro Colorado Island in Panama, we have eight censuses spanning 35 years, long enough to examine decadal changes in tree growth rates and death rates. The censuses of the 50-hectare plot began just as the island suffered one of the worst droughts in a century, and we observed both elevated tree growth rates and death rates during the drought (Condit et al. 1992b, 1995, 1996b; Leigh et al. 1990). In addition, the sapling population density of the forest declined by 15\%, though this happened after the drought, from 1990-2000. With a longer time frame now available, we can examine whether the forest recovered from the drought or was further impacted by subsequent droughts, as we suggested might happen (Condit 1998a).

Our focus is demographic recovery after the 1980s drought. Did mortality and growth rates subsequently stabilize to a baseline after 1990, as if 1983 was an unusual perturbation? Has sapling density increased back to the 1982 level? Or have droughts recurred and forced longterm changes? To test these hypotheses, we examine how demographic rates of the forest varied across two time intervals, from 1982-1990 and then from 1990-2015. Once testing for recovery in the forest as a whole, we ask how many individual species responded similarly. By the mid-1990s, we had found that many species had higher mortality during the drought period then five years later, but not all (Condit et al. 1995), and likewise, though many populations declined between 1982 and 1990, some species increased in abundance (Chisholm et al. 2014). Other studies of tropical forest and climate have variously focused on similarity (Clark and Clark 1994; Williamson et al. 2000) or differences between species responses (Enquist and Leffler 2001; Newbery and Lingenfelder 2009; De Cauwer et al. 2016).

To test for two phases of demographic fluctuations through time, we employ piecewise regression (McGee and Carleton 1970). The piecewise method can identify two portions of a regression with two different slopes, while simultaneously estimating the time at which the shift occurred. It can also reject a two-phase model, and thus demonstrate either no change or monotonic change through time. Piecewise regression is thus ideal for testing the hypotheses about drought recovery.

\section{Methods}

Plot and census

The 50 ha plot on Barro Colorado Island was established in 1981 and fully censused in 1982 then every 5 years from 1985 through 2015 . All stems $\geq 1 \mathrm{~cm}$ diameter-atbreast-height ( $\mathrm{dbh}$ ) were mapped, measured, and identified in each census (Hubbell and Foster 1983; Condit et al. 2012). Counting as individuals every genet, meaning genetic individuals with one or more stems, we have tagged a total of 423,617 individual trees. Though every stem is measured, here we only make use of the largest stem per individual, and growth rates are included only when the same stem was measured at the same height in consecutive censuses. Trees are counted dead when all stems died.

\section{Changing methods}

Our goal is to document long-term trends in forest demography, and it is thus crucial we use comparable methods across all eight censuses. Starting in 1990, we settled on consistent methods and published them in detail (Condit 1998b). During the first two censuses, however, refinements were made where needed. We address here three concerns where improvements meant changing methods.

\section{DBH precision in saplings}

Stems $<55 \mathrm{~mm}$ dbh were measured with $5-\mathrm{mm}$ precision in 1982 and 1985, and 1-mm precision since (all larger stems were always measured with 1 -mm precision). Condit et al. (1993b) discuss in detail growth estimates associated with a shift in precision. Here we bypass the problem by using only stems $60-79 \mathrm{~mm}$ dbh to analyze sapling growth, because they were always measured in the same way.

\section{DBH around buttresses}

In 1982, dbh was recorded at $1.3 \mathrm{~m}$ above the ground even in trees with large buttresses, but starting in 1985, all measurements were above buttresses where the bole was regular. The height at which trees were measured in 1982 and 1985 was always recorded, and we omit growth records where the point-of-measure changed between censuses. Here, we minimize the impact of excluding many buttressed trees in $1982-1985$ by using only trees $30-50 \mathrm{~cm}$ dbh across all census intervals to analyze canopy-level growth.

\section{Census dates}

Since 1985, the 50-ha census proceeded identically, always starting in the southwest and proceeding east, and always finishing in 10-11 months. As a result, the census interval for individuals never differed much from 5 years. But a much longer census was unavoidable in 1982 when all trees were tagged. One full pass lasted from March, 1981, until August, 1982, then, since a 50-ha census was much larger than any prior and we were concerned about missing trees, a second pass was done between August, 1982, and March, 1983. A few new individuals were added $(<5 \%$ of the total). This meant the 1982-1985 time interval for individual trees was as little as 2.5 years and as long as 4 years. It was unfortunate that the unusual drought of 1983 
fell during this first census interval, but that could not be planned. We have carefully examined notes from the first census to be certain that we have the date on which each tree was observed alive and measured, and all growth rates and death rates are calculated from individual census dates.

\section{Climate and dry season}

The Smithsonian Environmental Sciences Program maintains a weather station on Barro Colorado Island, and the Panama Canal Authority collects rainfall data throughout the canal watershed. With the two sources combined, we have daily records on Barro Colorado since 1929 (Engelbrecht et al. 2007). Potential evapotranspiration (PET) was estimated from a pan on the island since 1994, and the daily average was taken from 1994-2007 and assumed to hold every year. Throughout the entire period, daily water deficit was measured as observed rainfall minus the average potential evapotranspiration (PET) for the same date. A cumulative deficit was calculated as the sum of daily deficits over any set of consecutive days. Starting on 30 September each year (well before the dry season), the set of consecutive days for which the cumulative deficit reached its most extreme was identified, and that deficit defined the year's dry season (Engelbrecht et al. 2007). Daily minimum and maximum temperatures are available from the Barro Colorado weather station since 1970.

\section{Demographic analyses}

We wish to test how death rates, growth rates, and population sizes, for the entire stand and for every species, changed through time. For growth and death, we utilize the seven consecutive census intervals, and for population size, the eight censuses. A simple trend through time would be described using linear regression, where the demographic variable is the response and time the predictor. We wished, however, to expand the hypothesis to consider whether demographic traits followed two different trends, shifting in slope after the drought. To this end we employed piecewise regression, a tool producing an objective test of whether a linear regression slope shifts somewhere on the $x$-axis. The method simultaneously identifies the two trend slopes and the position on the $x$-axis where the shift occurs, that is, it identifies a model consisting of two lines connecting at any interior value of $x$ that best fits the observations. Statistical tests are possible by calculating credible intervals on all slope parameters. When a credible interval did not overlap zero, we conclude there was a significant change through time, and when credible intervals from two phases did not overlap, we conclude that the twophase model is a better fit to the data then a simple linear regression.
Piecewise regression with two phases is a fourparameter model describing the response of an independent variable $y$ as a function of a single predictor $x$,

$$
\hat{y}= \begin{cases}y_{b}+a_{1}\left(x-x_{b}\right) & x<x_{b} \\ y_{b}+a_{2}\left(x-x_{b}\right) & x \geq x_{b}\end{cases}
$$

where $\hat{y}$ means the predicted $y, a_{1}$ is the slope of the response in phase $1, a_{2}$ is the slope of the response in phase $2, x_{b}$ is the breakpoint, the $x$ at which the slope changes, and $y_{b}$ is $\hat{y}$ at the breakpoint. In our model, $x$ is time, and we defined it as the calendar year minus 1997 so that it was centered near zero. The time assigned an individual in one census interval was the mid-point between the two dates the tree was measured, expressed in years; this includes dead trees, which had an exact census date. For the purpose of graphing, observed or modeled demographic rates in a census interval were plotted at the mean of the mid-points for all individuals in the analysis.

\section{Demographic measures}

The response variables were demographic rates and abundances. Mortality was defined as the mortality rate constant, $m$, which is the negative of the logarithm of annual survival,

$$
m=\frac{\log \left(N_{0}-S_{t}\right)}{t},
$$

where $S_{t}$ is the number of survivors at time $t$ in a cohort that began (at $t=0$ ) with $N_{0}$ trees (Condit et al. 1999). The time interval $t$ was calculated as the mean number of days between censuses of the $N_{0}$ trees, converted to a year. Growth rates were defined for each individual tree as $\mathrm{dbh}$ increment, or

$$
g=\frac{d_{t}-d_{0}}{t}
$$

where $d_{t}$ is dbh at time $t$ (Condit et al. 1999). Abundance was defined simply as the total number of individual trees in 50 ha.

\section{Data transformation}

Modeling $g$ is difficult statistically because of two associated features. First, the distribution of $g$ is extremely right skewed, which routinely calls for logarithmic transformation. Unfortunately, however, we often observe $g<0$, caused by small errors in dbh but also falling bark or other stem damage. We know that error can account for many negative growth rates, because we did double-blind remeasurements of 4070 randomly selected trees. The SD of repeated measurements, $\sigma_{e}$, was $\sim 1 \mathrm{~mm}$ in saplings, greater than mean sapling growth rate $\left(\sigma_{e}\right.$ is described in more detail below), and it is thus not surprising that $21.1 \%$ of 66191 sapling measurements analyzed had $g \leq 0$. The simplest approach is to convert the non-positive rates to a number below the minimum observable growth of $1 \mathrm{~mm}$ 
in 5 years (Condit et al. 1993a, 2006). But with 21\% of rates so converted, the resulting distribution of transformed $g$ is highly sensitive to that minimum. Choosing $0.01,0.05$, or $0.1 \mathrm{~mm} \cdot \mathrm{y}^{-1}$ alters the skewness of log-transformed growth.

An alternative transformation for right-skewed distributions is by a power $<1$, that is

$$
g_{t}=g^{\lambda} \text {, }
$$

where $g_{t}$ is a transformed growth rate and $\lambda<1$ (Tukey 1957). The advantage of this method is that it works smoothly for negative growth rates as

$$
g_{t}(\lambda)= \begin{cases}g^{\lambda} & g \geq 0 \\ -\left\{(-g)^{\lambda}\right\} & g<0 .\end{cases}
$$

This is known as the modulus transformation (John and Draper 1980). It reigns in negative growth outliers in the same way that it does for positive growth. We found that in the range $\lambda \in(0.3,0.6)$, transformed growth rates have low skewness, and median and mean are close. For any sample of growth increments, a $\lambda$ can be located that minimizes skewness, but we sought one value that worked reasonably for all species and dbh categories. The main purpose is to reign in the big outliers that can cause peculiar model results, and $\lambda=0.4$ was satisfactory for both saplings and large trees.

All modeling was thus done with $g_{t}(0.4)$, but we prefer presenting the original growth rates $g$ via backtransformation. Arithmetic means do not back-transform, that is

$$
\hat{g} \neq \widehat{g}_{t}^{1 / \lambda}
$$

where $\hat{g}$ is the arithmetic mean. The same problem holds for log-transformations. But medians back-transform exactly, so the model results represent median dbh increments in $\mathrm{mm} \cdot \mathrm{y}^{-1}$ per dbh category. Due to high skewness, median growth is well below mean growth, even at a fixed dbh (Kenfack et al. 2014), and the median is arguably a better statistic to present, in the same way that summaries of income are often presented as medians, not means.

The modulus transformation allows negative growth rates to be included, but there were extreme errors, both negative and positive, that were excluded. Any growth rate amounting to a dbh increment $>75 \mathrm{~mm} \cdot \mathrm{y}^{-1}$ was discarded, since this was the highest rate observed with confidence in Ochroma pyrimidale, Trema spp., and Cecropia spp., the fastest growing species in the forest. Negative outliers were also eliminated based on the measurement error we estimated from the 4070 double-blind remeasures, $\sigma_{e}$, modeled as a function of dbh $d: \sigma_{e}=0.006214 d+0.9036$. Any stem whose later measurement fell $<4 \sigma_{e}$ below the earlier measurement was considered an extreme error. These extremes happen either when a decimal is misplaced, or when the wrong tree is measured, the latter plausible when two stems are in contact. Details on the procedures for estimating error and filtering extreme growth rates are given in Condit (1998b) and Condit et al. (2004).

Population sizes were modeled after log-transformation. The mortality rate parameter is already a logarithm, and thus was not further transformed.

\section{Diameter categories}

To eliminate dbh as a predictor of mortality and growth and to assess how understory and canopy trees responded differently, all tests were done separately on several dbh categories. Since growth rate increases substantially with $\mathrm{dbh}$, we used three narrow dbh categories for growth analyses: $[6,8),[10,15)$, and $[30,50) \mathrm{cm}$. Mortality rate varies only slightly with $\mathrm{dbh}$, so two wider categories were employed: $[1,10)$ and $\geq 10 \mathrm{~cm}$. Abundance was also considered in the latter two categories. The dbh category of a tree was redefined at every census, meaning trees changed categories if they grew enough, and trees entering the census for the first time were always included. For mortality and growth analyses, dbh category was defined based on the earlier of the two censuses on which the calculation was based.

\section{Species included}

Over eight censuses, a total of 321 taxa were consistently identified. Species were included in analyses, however, only if they had a demographic measure in every census or census interval, meaning rare species were omitted when they were absent in one or more censuses. For some analyses, we report observed or fitted demographic rates in the more common species, those averaging at least 50 individuals alive over the eight censuses in a single dbh interval, and some graphs highlight the most abundant species in any category.

\section{Modeling demography through time Multi-level model}

The piecewise regression model was run in an hierarchical, or multi-level, framework: species within the community. The parameter estimates (see Eq. 1) for all the species were thus assumed to form a multi-dimensional Gaussian distribution, ie a hyper-distribution. Define $\boldsymbol{\theta}_{k}=\left(a_{1}, a_{2}, x_{b}, y_{b}\right)$ as the set of four piecewise-regression parameters for species $k$, then our assumption is that $\boldsymbol{\theta}_{k} \sim \operatorname{Norm}\left(\right.$ Mean $\left.=\hat{\boldsymbol{\theta}}, \mathrm{SD}=\boldsymbol{\sigma}_{\theta}\right)$. The multivariate mean $\hat{\boldsymbol{\theta}}$ and standard deviation $\boldsymbol{\sigma}_{\theta}$ are called hyperparameters. They describe the community-wide mean and $\mathrm{SD}$ of species responses. In the terminology of randomeffect models, the hyperparameters are the fixed effects and species parameters are random effects (Gelman and Hill 2007). 
We have used hierarchical models in analyzing species demography in the 50-ha plot for many years (Condit et al. 2006; Rüger et al. 2009, 2011a, b). It works well because the large number of rare species cannot be analyzed independently, but the hierarchical approach allows them to be included. The multi-level approach combines species responses, so each species is supported by the others, but still allows the response of species to differ. Gelman and Hill (2007) describe this as partial pooling, where complete pooling means analyzing the community as a whole, effectively ignoring species, while the opposite, no pooling at all, would be analyzing all species separately, requiring many rare species to be omitted. The latter was our approach in analyzing demography in papers prior to 2005 (Hubbell and Foster 1990; Condit et al. 1992a, 1995, 1996a, c, 2004). In a sense, in the multi-level model, the entire community serves as a prior for the response of any one species. For rare species, that prior is important and can dominate the result. But for species with ample data, the prior exerts little pull.

\section{Model fitting}

One model covered one demographic rate (mortality, growth, or abundance) across all species in a single dbh category. The following parameters and equations refer to a single size class, and subscripts identifying dbh category are supressed for easier presentation.

In order to fit parameters in a Bayesian framework, likelihood functions describing the probability of all observations given the model and any set of parameters must be defined. Write the piecewise regression function for species $k$ compactly as $f$, so a predicted demographic parameter is

$$
\widehat{y_{k}}=f\left(x, \boldsymbol{\theta}_{k}\right),
$$

with $\boldsymbol{\theta}_{k}$ the set of four regression parameters for species $k$ and $x$ is time (of a census or mid-point between consecutive censuses). The prediction, $\widehat{y_{k}}$, refers to either the mortality parameter $m$, transformed growth $g_{t}$, or logarithm of abundance.

For the growth and abundance models, the likelihood function for species $k$ is

$$
\begin{aligned}
L_{k}= & \sum_{i} \log \left[\operatorname{Norm}\left(y_{i}, \text { Mean }=\widehat{y_{k}}, \mathrm{SD}=\epsilon\right)\right] \\
& +\log \left[\operatorname{Prob}\left(\widehat{y_{k}}\right)\right],
\end{aligned}
$$

where Norm means the Gaussian probability of one observation $y_{i}$ given the predicted $\widehat{y_{k}}$ and a residual error, $\epsilon$. For growth, the observation is a single tree of species $k$ in one census interval and the summation is thus across all individuals in a census then across censuses. For abundance, the observation is the population size of species $k$ in one census and the summation is across censuses. The residual requires another parameter, but just one more because we assume it is identical for all species, standard in multilevel models (Gelman and Hill 2007). The term Prob $\left(\widehat{y_{i}}\right)$ is the hyper-probability of the predicted $\widehat{y_{k}}$, defined below (Eq. 10).

The likelihood function for mortality differs because it is a binomial process, so

$$
\begin{aligned}
L_{k}= & \log \left[\operatorname{Binom}\left(S_{k}, \text { Mean }=e^{-\widehat{y_{k}} t}, \text { Size }=N_{k}\right)\right] \\
& +\log \left[\operatorname{Prob}\left(\widehat{y_{k}}\right)\right],
\end{aligned}
$$

where $S_{k}$ is the number of survivors observed of $N_{k}$ individuals over a census interval of $t$ years, in species $k$. Binom is the binomial probability of observing $S_{k}$ out of $N_{k}$ given mean survival $e^{-\widehat{y_{k}} t}$. The residual $\epsilon$ is no longer needed.

Whether mortality, growth, or population size, the total log-likelihood of observations is the sum of all the species' log-likelihoods, $L=\sum_{k} L_{k}$. To accommodate the hierarchical aspect, another likelihood function must be written for the hyperparameters,

$$
\begin{aligned}
H & =\log \left[\operatorname{Prob}\left(\widehat{y_{k}}\right)\right] \\
& =\sum_{k}\left[\log \left(\operatorname{Norm}\left(\widehat{y_{k}}, \text { Mean }=\hat{\boldsymbol{\theta}}, \mathrm{SD}=\boldsymbol{\sigma}_{\theta}\right)\right] .\right.
\end{aligned}
$$

Equation 10 covers the four regression parameters, because $\hat{\boldsymbol{\theta}}$ is the vector of four means and $\boldsymbol{\sigma}_{\theta}$ the vector of four standard deviations (we ignored covariance among the parameters). The full likelihood of an entire set of model parameters combines the likelihood of the observations and the likelihood of the hyperparameters,

$$
\Theta\left(\boldsymbol{\theta}_{k}, \hat{\boldsymbol{\theta}}, \boldsymbol{\sigma}_{\theta}, \epsilon\right)=H+L \text {. }
$$

With $S$ species, there are $4 S+9$ parameters needed for the full likelihood $\Theta$ in growth and abundance models, and $4 S+8$ (without $\epsilon$ ) for mortality. Priors for all parameters were assumed to be non-informative. Every valid value was equally likely.

\section{Parameter fitting}

We used a Bayesian parameter-fitting method, sampling the posterior distributions by repeated Metropolis updates based on the full likelihood function (Eq. 11), generating Monte-Carlo Markov chains of each parameter. The MCMC chains represent full posterior distributions of all parameters and of other estimators derived from parameters. Chains were run 12000 steps for each model, examined visually for mixing, and the initial 2000 steps discarded as burn-in. We report the mean of post-burn-in chains as best estimates, and quartiles 0.025 and 0.975 for 95\% credible intervals. Hypotheses were tested by checking whether credible intervals of one slope parameter overlapped zero, or whether credible intervals of two slope parameters for one species overlapped each other. 


\section{Drought impact score}

As in Newbery and Lingenfelder (2009), we estimated a drought impact score for every species using its estimated growth and mortality rates. Fitted parameters of the piecewise regression model were plugged in Eq. 1 for every species and every diameter category to estimate the demographic rates in the first census interval ( $x=-14$, which is year 1983 and during the drought) and the third interval ( $x=-5$, after the drought). The difference in the estimated rates, early minus late, indicates drought impact. With mortality in two dbh categories and growth in three, there were five measures per species. We checked correlation among the measures, and then tested whether drought impact scores were significant predictors of population performance both during and after the drought, also estimated from piecewise regression.

\section{Results}

\section{Climate and dry season}

The harshest dry season since 1931 was during the El Niño of 1983, when the cumulative moisture deficit reached $-674 \mathrm{~mm}$ (Fig. 1). Mean PET during the dry season was $5.6 \mathrm{~mm} \cdot \mathrm{d}^{-1}$, so this would be equivalent to 120 days with no rain. In fact, there were 16 consecutive weeks without rain, and temperatures were unusually high (Leigh et al. 1990). The start date of 13 November 1982 was the earliest in the record. After 1983, harsh dry seasons, those with a moisture deficit at least 1 SD drier than the mean, followed in 1985, 1988, 1989, and 1992. The 1997-1998 El Niño was drier than normal, but not as harsh as any of the droughts of the late 1980s, and after 2003, no dry season surpassed 1 SD drier than the mean (Fig. 1).

The temperature record at Barro Colorado showed no warming over the census period, from 1980-2015. Neither maximum nor minimum temperature showed a trend.

\section{Mortality}

\section{Observed mortality}

In trees $(\geq 10 \mathrm{~cm} \mathrm{dbh}$ ), stand-level mortality declined from a peak during the 1983 drought interval. After 1990, however, the trend reversed, and mortality rate increased over the next 20 years, though never returning to the early peak (Table 1). Common species showed similar trends, as illustrated for the eight most abundant (Fig. 2a). Beyond those, of the sample of 78 species with $\geq 50$ individuals (average per census), most had their peak of observed mortality in either the first interval ( 29 species) or the last (24 species).




Table 1 Abundances and demographic rates in the 50 ha plot in eight censuses, or seven census intervals (rates appear beneath the second census of an interval)

\begin{tabular}{|c|c|c|c|c|c|c|c|c|c|}
\hline Demographic measure & Category & 1982 & 1985 & 1990 & 1995 & 2000 & 2005 & 2010 & 2015 \\
\hline \multirow[t]{2}{*}{ Observed individual density $\left(\mathrm{ha}^{-1}\right)$} & Sapling & 4285.1 & 4424.1 & 4453.7 & 4149.8 & 3849.8 & 3748.7 & 3726.9 & 3734.8 \\
\hline & Tree & 416.1 & 412.9 & 423.5 & 428.0 & 422.8 & 416.0 & 414.6 & 415.3 \\
\hline \multirow[t]{4}{*}{ Median species abundance (50 ha) } & Observed sapling & 135.0 & 115.0 & 109.5 & 99.0 & 90.0 & 90.5 & 104.5 & 104.5 \\
\hline & Fitted sapling & 134.0 & 126.2 & 114.8 & 105.3 & 101.3 & 105.2 & 109.2 & 113.5 \\
\hline & Observed tree & 31.0 & 30.0 & 28.5 & 27.5 & 29.5 & 30.5 & 29.0 & 30.0 \\
\hline & Fitted tree & 31.3 & 31.1 & 30.9 & 30.7 & 30.4 & 30.1 & 29.9 & 29.6 \\
\hline \multirow[t]{4}{*}{ Mortality rate $\left(\% \cdot y r^{-1}\right)$} & Observed sapling & & 2.64 & 2.24 & 2.55 & 2.81 & 2.36 & 2.37 & 2.44 \\
\hline & Fitted sapling & & 4.81 & 4.76 & 4.70 & 4.65 & 4.61 & 4.57 & 4.54 \\
\hline & Observed tree & & 2.73 & 1.95 & 1.87 & 2.08 & 2.29 & 2.26 & 2.46 \\
\hline & Fitted tree & & 3.27 & 2.60 & 2.49 & 2.63 & 2.78 & 2.92 & 3.07 \\
\hline \multirow[t]{6}{*}{ Median growth rate $\left(\mathrm{mm} \cdot \mathrm{yr}^{-1}\right)$} & Observed sapling & & 1.18 & 0.98 & 0.62 & 0.60 & 0.60 & 0.61 & 0.78 \\
\hline & Fitted sapling & & 1.17 & 0.82 & 0.50 & 0.58 & 0.67 & 0.78 & 0.89 \\
\hline & Observed mid-sized tree & & 1.70 & 1.34 & 1.04 & 1.00 & 1.01 & 1.00 & 1.16 \\
\hline & Fitted mid-sized tree & & 1.80 & 1.44 & 1.14 & 1.21 & 1.29 & 1.37 & 1.45 \\
\hline & Observed large tree & & 5.69 & 3.56 & 2.74 & 2.80 & 2.78 & 2.66 & 2.75 \\
\hline & Fitted large tree & & 6.05 & 3.70 & 2.76 & 2.82 & 2.88 & 2.94 & 3.00 \\
\hline
\end{tabular}

Observed medians of species abundances are based on all species in each category used in the modeling (see Methods). Fitted median abundances (the fixed effect) are from the piecewise hierarchical model. Because species was a random effect, the fixed effect is the mean of all species medians

In saplings $(1-10 \mathrm{~cm} \mathrm{dbh})$, there was no consistent trend in stand-wide mortality over 30 years. Mortality was higher during the 1983 drought than over the next 10 years, but the 1995-2000 census had the highest sapling mortality in the entire period (Table 1). After 2000, sapling mortality remained intermediate. Abundant species illustrated in Fig. 2b suggest the lack of a consistency. In a wider sample of 173 species averaging at least 50 saplings per census, there were 48 having peak mortality in the first interval, but a larger number (57 species) had peak mortality in the middle interval, 1995-2000.

\section{Modeled mortality}

Piecewise regression clearly supported a shift in the mortality trend of large trees in 1990, mirroring the observed rates for the entire stand and common species (Fig. 3a). The fixed effect, or the mean of all the species responses, showed a decrease from $3.27 \% \cdot \mathrm{y}^{-1}$ to $2.49 \% \cdot \mathrm{y}^{-1}$ during the $1980 \mathrm{~s}$, then an increase to $3.07 \% \cdot \mathrm{y}^{-1}$ by 2010 ; both slopes were significantly different from zero. The break point of the fixed effect, where the slope changed, was estimated with precision, having $95 \%$ credible intervals of 1989-1990 (Fig. 3a). Modeled large-tree mortality rates of nearly every individual species showed a parallel trend, with 209 of 211 species having decreasing mortality shifting to increasing; 40 of those had a significant decline in mortality during the early phase, and 44 a significant increase in the later phase.
The regression model for saplings showed no shift in the mortality trend through time (Fig. 3b). The fixed effect (mean of species means) declined slightly from $4.81 \% \cdot y^{-1}$ to $4.56 \% \cdot y^{-1}$ over the entire 30 years, but the slopes of the two phases were not statistically different from zero. The 259 individual species showed all possible responses, including 43 with steadily increasing mortality and 78 with steadily decreasing (the rest switched from decreasing to increasing or vice versa).

\section{Growth}

\section{Observed growth}

Each of the size categories we investigated showed similar patterns of observed growth through time (Fig. 4). Growth was highest during the 1983 drought, declined quickly by 1990 , then reversed and increased slightly through the last census, though this pattern was less pronounced in the mid-sized category $(10-15 \mathrm{~cm} \mathrm{dbh})$. Most of the commonest species showed a similar trend of declining growth over 10 years, then little subsequent change or a slight increase over the next 20 years (Fig. 4).

\section{Modeled growth}

Piecewise regression clearly supported this shift in the growth trend (Fig. 5). The fixed effect, or the mean of the species medians, initially declined significantly in all three dbh categories, then switched to a positive trend in all three dbh categories, statistically different from zero 


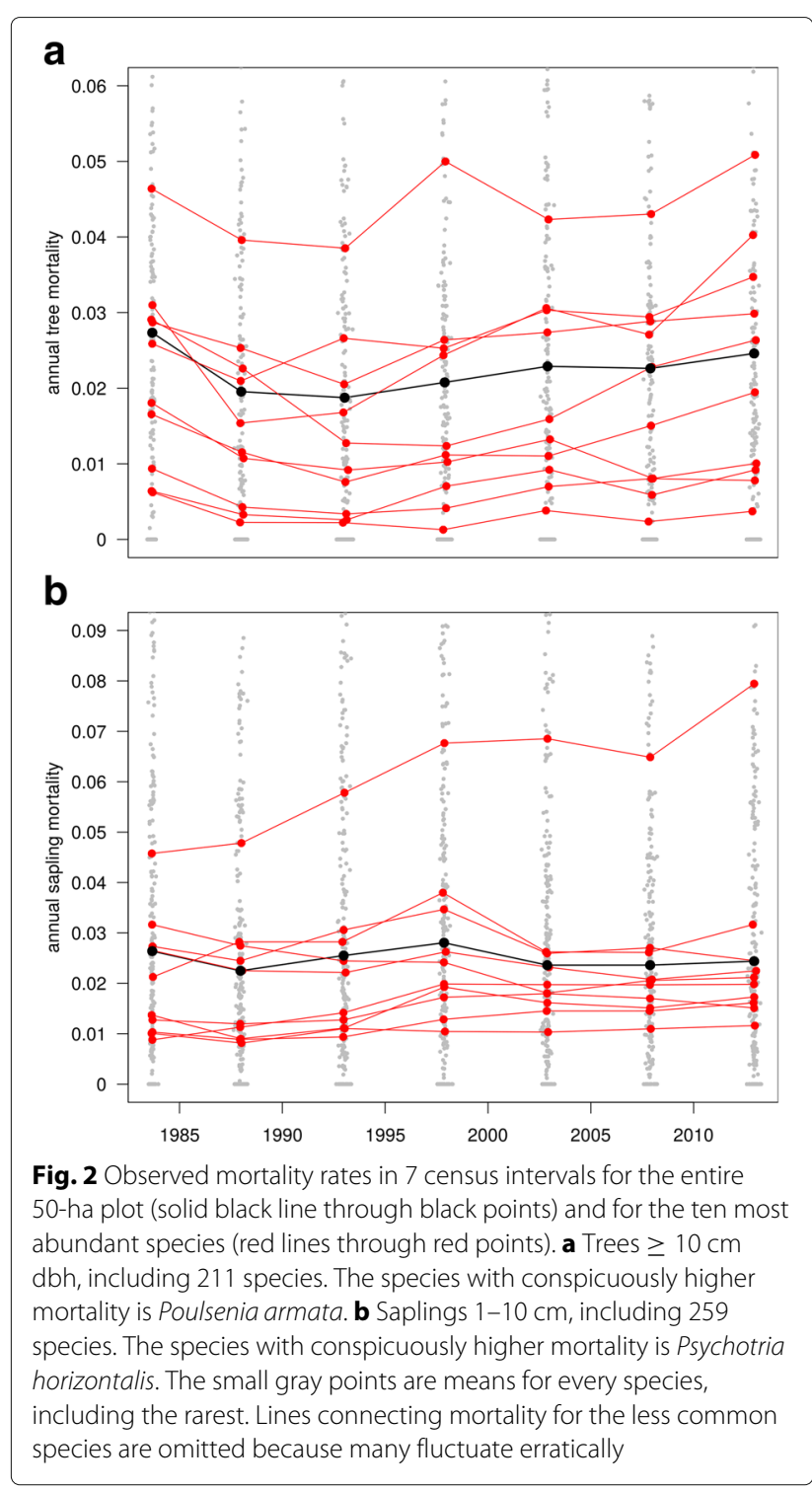

in saplings and mid-sized trees but not large trees. The year of the shift was estimated between 1990 and 1993 in all categories. Individual species were consistent in these trends (Fig. 5). In the majority of all species, the change in slope of the growth trend changed significantly between 1988 and 1995.

\section{Population size}

\section{Observed abundance}

Over the 35 years of censuses, the number of living trees $\geq 10 \mathrm{~cm} \mathrm{dbh}$ of all species fluctuated irregularly around 420 individuals $\cdot$ ha $^{-1}$ (Table 1). Saplings, however, fluctuated considerably. For the first three censuses, 1982-1990, the number climbed slightly, by 169 saplings.ha ${ }^{-1}$ (4\% of the total density). It then declined for 20 years, reaching a nadir in 2010 that was $17 \%$ lower than the 1990 peak.



In the final census, 2015, the density of saplings finally increased again, but only slightly (Table 1 ).

\section{Modeled abundance}

In trees, the fixed effect from the piecewise regression confirmed stable density over the 35 years. Some individual species did, however, fluctuate, but in all possible directions. For example, 31 of the 204 species had responses that changed significantly between two phases, but equally divided between those increasing in abundance then stabilizing or declining (16 species), and those decreasing then recovering ( 15 species).

The signal of decreasing sapling density was highlighted by the model, which demonstrated a significant decline in density followed by a significant increase, shifting in 1997. Individual species responses were slanted in the same direction. For example, 68 of 256 species showed 


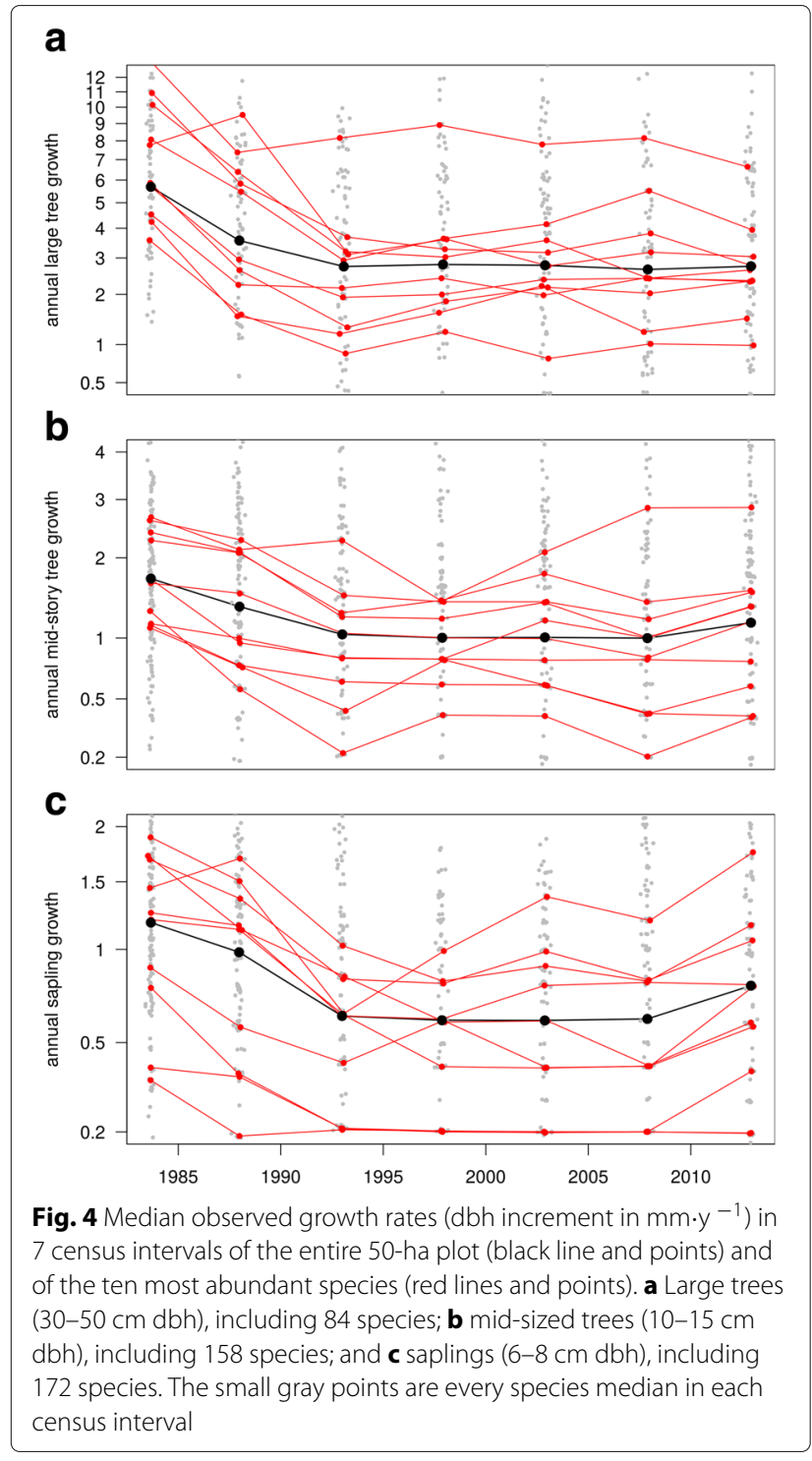

significant shifts in slope of abundance through time, and 61 of those switched from substantial declines in abundance to stabilization or increase. Nevertheless, there were species whose sapling populations followed every pattern, and we can identify species whose populations rose then stabilized or declined etc. Figure 6 illustrates examples of abundant species having sharp population shifts.

\section{Drought impact measures \\ Correlation among measures}

The drought impacts on mortality rate in two size classes were positively correlated across species, that is, species suffering higher sapling mortality during the drought also suffered higher tree mortality during the drought. Growth impact was also positively correlated between saplings and mid-sized trees, and between mid-sized trees and
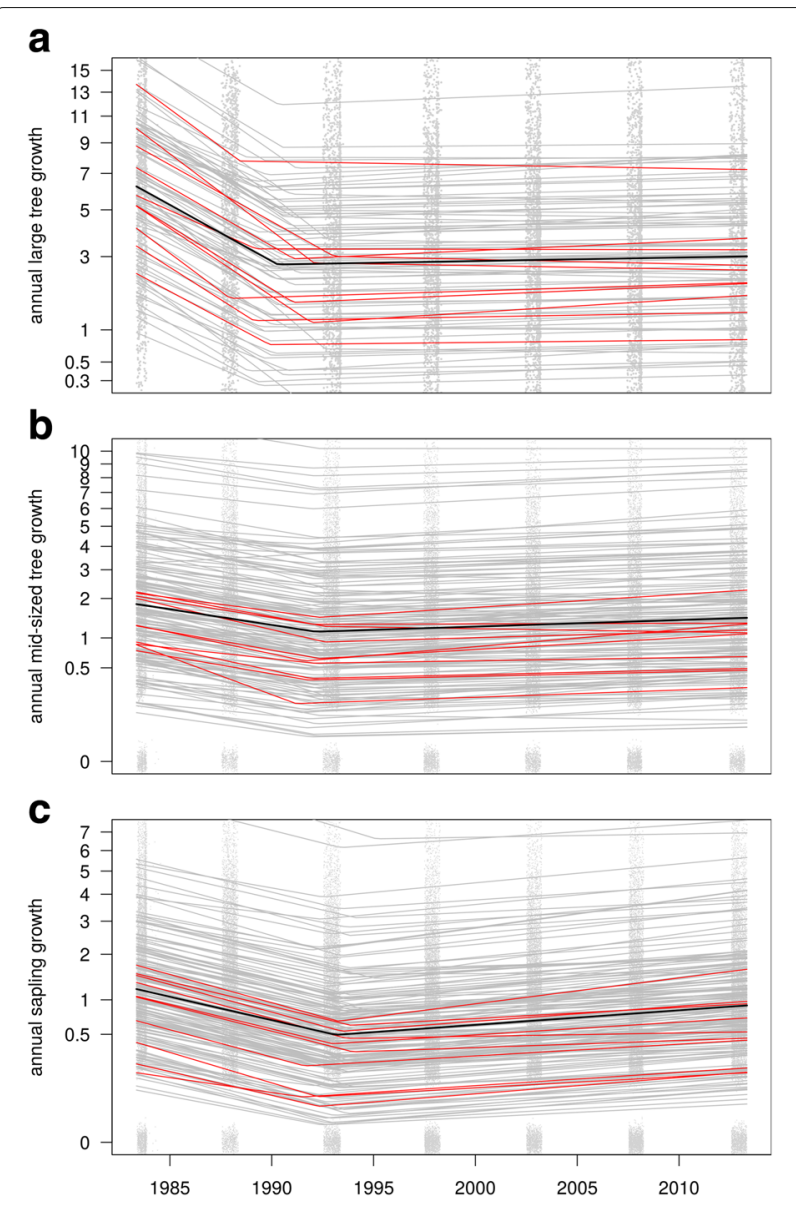

Fig. 5 Median growth rates fitted by piecewise regression. Diameter increment $\left(\mathrm{mm} \cdot \mathrm{y}^{-1}\right)$ was power-transformed for modeling, but the rates shown here are back-transformed. The black lines are fixed effects, or the mean of species medians. The red lines are median growth rates of the ten most abundant species. Gray lines in the background show the fitted growth response for every species, and small gray points are growth rates of individual trees (appearing as gray vertical bands at each census interval). a Large trees $(30-50 \mathrm{~cm}$ $\mathrm{dbh}), \mathbf{b}$ mid-sized trees (10-15 cm dbh), and c) saplings ( $6-8 \mathrm{~cm} \mathrm{dbh})$

large trees, but not between saplings and large trees. The drought impact on mortality did not correlate with the drought impact on growth in any size class.

\section{Predicting population trends}

The only demographic measure of drought impact that predicted population trends during the 1980s was mortality in saplings (Fig. 7a). Species suffering the most excess drought mortality had large population declines during 1982-1990, then reversed and increased after 1990 (Fig. 7b). Since populations can only decline from mortality, and population changes were most pronounced in saplings, the trend in the 1980s is not surprising, but the weak positive trend after 1990 is not a necessary corollary. Mortality impact in larger trees was negatively correlated 




with population trend during the 1980s, but not significantly so $(p=0.13)$. Drought impact on growth did not correlate with population trends during the 1980s.

\section{Discussion and conclusions}

In the early 1990s, we described the BCI forest's response to a 1983 El Niño drought. Tree mortality was higher during the first census interval, 1982-1985, relative to 19851990, and somewhat surprisingly, growth rates were also higher during the drought. Through the 1990-1995 interval, mortality and growth rates continued to decline, suggesting that some drought-induced mortality was delayed by several years after 1983, causing (partly) elevated mortality in 1985-1990. We were keen to repeat observations of droughts, and the El Niño forecast for 1997 led us to repeat plot censuses at $\mathrm{BCI}$ and two other sites just before and after. There was a slight increase in growth during that
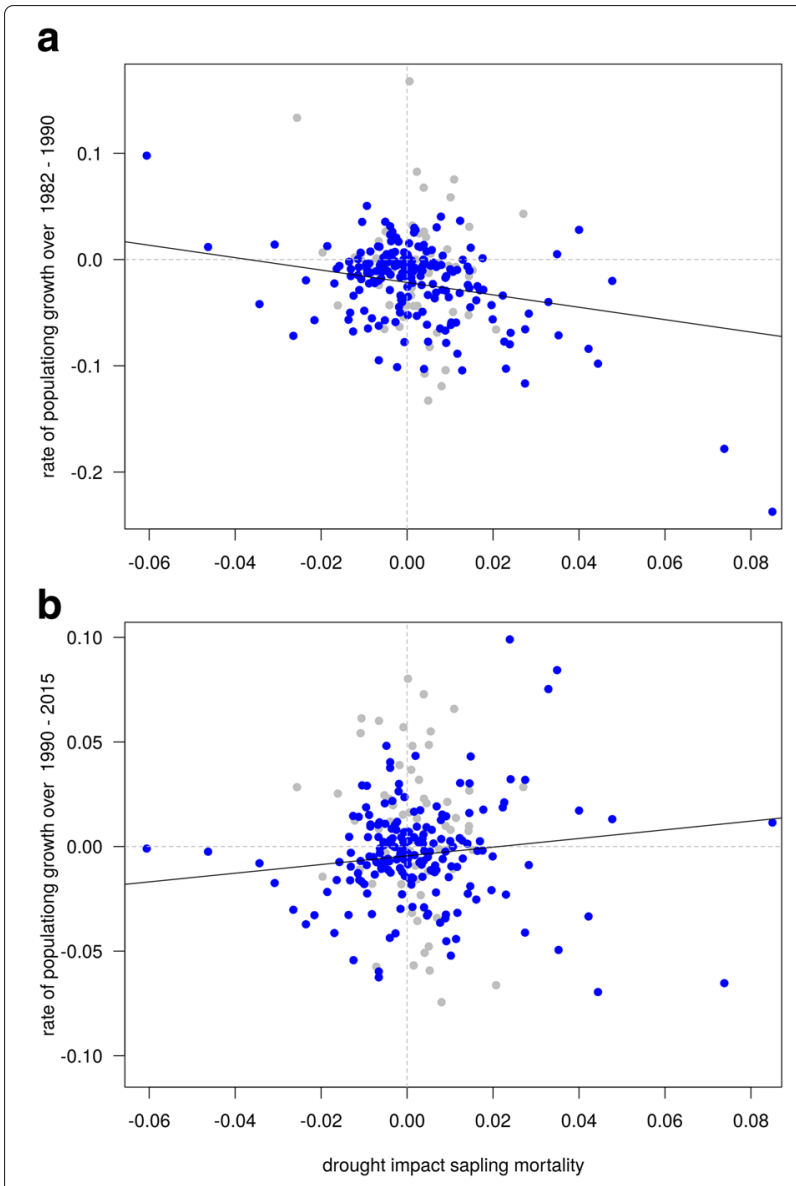

Fig. 7 Correlation between the drought impact on sapling mortality ( $x$-axis) and annual rate of sapling population change over two census intervals: a) 1982-1990 and b) 1990-2015. Drought impact was measured as the difference in fitted mortality rate during the first minus the third interval for every species, so positive indicates species that suffered most during the drought. Population growth was also measured from fitted abundances. All species shown by gray points, and those with $\geq 50$ individuals by blue. Solid lines are regressions: a) $\left.p<0.0001, r^{2}=0.082 ; \mathbf{b}\right) p=0.01, r^{2}=0.026$, both based only on those more abundant species

1997 drought, but no impact on mortality (Condit et al. 2004).

In the mid-1990s, we laid out the possibility that drought frequency might increase with anthropogenic climate stress and described how a moist forest such as Barro Colorado would change (Condit et al. 1996b, 1995; Condit 1998a). Others have picked up this theme and even cited BCI as an example of drought-induced tree death (Allen et al. 2010; Phillips et al. 2010). In retrospect, our prediction has not been borne out. There has not been an increase in drought stress. The 1980s passed, and the forest has largely returned to a non-drought dynamic. The elevated mortality and growth we detected in the first census interval have not been repeated. 
The observation of high tree mortality during the drought was unsurprising, as it has been observed in many forests, but elevated tree growth during the 1983 drought was not a prediction a priori. Drought stress might be expected to reduce growth, because this is a common result in tree-rings (van der Maaten-Theunissen et al. 2016), however, 35 years of observations cement our conclusion. Growth rates of all dbh categories were highest during 1983, fell to a low during 1990-1995, and have since stabilized or increased slightly. The hypothesis we favor is that reduced cloudiness during 1983 stimulated growth and reproduction (Wright et al. 1999). We suggest further that trees suffered with lower growth in 1990 due to resource expenditure during the 1980s (Hacket-Pain et al. 2015).

To a considerable extent, individual species demography followed the stand-level patterns closely. Nearly all species' growth rates were elevated during the drought, declined until the early 1990s, then stabilized or increased, and the same held for mortality rates of larger trees. Saplings, however, were much different, displaying no consistent mortality trend. This is based on the hierarchical model using piecewise regression, so we consider closely how it should be interpreted.

We recognize that both growth and mortality rates are poorly constrained for the many uncommon or rare species. Growth rates of individual trees is highly variable, even in the same dbh category of one species, and low death rates require large samples to be estimated with precision. In isolation, no trend in a species with fewer than 20 trees carries weight. The hierarchical approach allows these species to contribute, not in isolation but by supporting each other. For any one species, the average trend of all other species is serving as prior information. The community-wide average is to a considerable extent set by the common species, but not completely. There are a lot of rare to uncommon species, and as a group they do exert an influence.

Common species nearly all followed community-wide trends of demography through time. A conservative way of interpreting results for rare species is that their results are consistent with the same trend - they do not reject it. In fact, the results of the hierarchical model are somewhat stronger than that, since they support the conclusion that uncommon species as a group showed similar trends to the community. But for individual rare species, we cannot draw conclusions.

Use of the hierarchical model with piecewise regression to describe population trends demonstrates that it does not force species into similar patterns. Indeed, modeled population trends of individual species were highly variable and covered every possible sequence of increase, decrease, or stability. We previously showed that species abundances in the BCI forest are not stable, since many species show declines or increases of 3\% per year or more (Hubbell and Foster 1992; Chisholm et al. 2014), including both increases and decreases. Piecewise regression added a wrinkle, since it identified species with two phases, either increasing then decreasing or vice versa, as well as monotonic change. Since our main hypothesis was recovery from drought, our focus is on those species that declined in abundance during an early phase, then reversed and showed stabilization or increase. Among saplings, many species showed this pattern.

In Condit et al. (1996b), we identified species associated with the moister sections of the BCI plot, in particular those with higher density on the steeper slopes, known to have more access to water during the dry season (Condit et al. 1995; Harms et al. 2001). Here we revisit this group to evaluate their recovery, considering 43 of those species that averaged over 50 individuals in the sapling category across all eight censuses. As we reported in Condit et al. (1996b), most (35 species) declined during the drought period, 1982-1990. Of those 35 losing population during the 1980s, 26 showed recovery and had population increases over 1990-2015. But the other nine continued to decline.

The most abundant of the slope specialists, Poulsenia armata, has been one of our prime examples of drought stress. It is a large canopy tree, always associated with moist slopes across central Panama. In 1982, its population was dense with saplings, suggesting ample recruitment during the 1970s, but most died over the next decade. It has not recovered: its total population fell from 3422 to 1774 over the period 1982-1995, and then even further, to 855 , by 2015 . The next most abundant of the slope specialists was Ocotea whitei, another tall tree, and it was a contrast in terms of recovery. Its population fell steadily from 1118 in 1982 to 374 in 2005, but then reversed and expanded to 381 by 2015 .

Viewed as a tree-ring record might be, with five-year precision, the 35 years of censuses in the BCI 50-ha plot showed a single peak in growth rate during the 1980s, then subsequently a stable growth rate. Unlike tree-ring records, we can show that tree mortality rates accompanied the cycle, though only in larger trees. And despite the high species diversity, we conclude that most species in the forest followed the same trends in growth and mortality, in contrast with Enquist and Leffler (2001) and Newbery and Lingenfelder (2009), who emphasized the diversity of responses.

We also conclude that some species suffered steep population declines as a result of the drought, with most, but not all, then recovering. Overall we observed a variety of population trajectories, though. So while the forest may have returned to a period of relative demographic stability after 1990, the species composition is not stable and is evidently changing for reasons we do not yet understand. 
Since 1990, growth and mortality rates crept back up, despite moderate climate with no temperature increase. These increases fit global trends in forest dynamics (Lewis et al. 2004), but given how much demography fluctuated over 35 years, we hesitate to draw simplistic conclusions about the possible impact of $\mathrm{CO}_{2}$ or which species or traits might be favored. Our understanding of long-term dynamics will undoubtedly evolve after another 35 years of plot censuses.

\begin{abstract}
Acknowledgments
We acknowledge Robin Foster as the lead field scientist setting up the Barro Colorado 50-ha plot, whose botanical expertise was essential over the first three censuses and whose guidance was essential for all us still working in the plot. The censuses have been made possible through support of the U.S. National Science Foundation (awards 8206992, 8906869, 9405933, 9909947, 0948585 to S.P. Hubbell), the John D. and Catherine D. McArthur Foundation, and the Smithsonian Tropical Research Institute. We also thank the dozens of field assistants and botanists who have measured and mapped the trees over the past 35 years.
\end{abstract}

\section{Authors' contributions}

RC directed the field work since 1991, organized all aspects of the database, carried out the analyses, and wrote the paper. RP managed all aspects of the field work since 1995, identified new trees, screened and corrected all data since, and contributed to the writing and the conclusions. SA managed all aspects of the field work since 1995, identified new trees, screened and corrected all data since, and contributed to the writing and the conclusions. SL designed and oversaw data entry since 1995, screened and corrected errors, and created and managed the database. SPH conceived the original project, organized and managed the first three censuses, raised nearly all funding over 35 years, helped design the major questions, and contributed to the writing and conclusions. All authors read and approved the final manuscript.

\section{Competing interests}

The authors declare that they have no competing interests.

\section{Author details}

${ }^{1}$ Field Museum of Natural History, 1400 S. Lake Shore Dr., Chicago, IL 60605, USA. ${ }^{2}$ Smithsonian Tropical Research Institute, Panama City, Panama. ${ }^{3}$ University of California, Los Angeles, California, USA. ${ }^{4}$ Morton Arboretum, 4100 Illinois Rte. 53, Lisle, IL 60532, USA.

Received: 13 June 2017 Accepted: 29 August 2017

Published online: 20 September 2017

\section{References}

Allen CD, Macalady AK, Chenchouni H, Bachelet D, McDowell N, Vennetier M, Kitzberger T, Rigling A, Breshears DD, Hogg ET (2010) A global overview of drought and heat-induced tree mortality reveals emerging climate change risks for forests. For Ecol Manag 259:660-684

Brienen RJW, Zuidema PA (2005) Relating tree growth to rainfall in Bolivian rain forests: a test for six species using tree ring analysis. Oecologia 146:1

Briffa KR, Jones PD, Bartholin TS, Eckstein D, Schweingruber FH, Karlén W, Zetterberg P, Eronen M (1992) Fennoscandian summers from ad 500: temperature changes on short and long timescales. Clim Dyn 7:111-119

Chisholm RA, Condit R, Rahman KA, Baker PJ, Bunyavejchewin S, Chen Y-Y, Chuyong G, Dattaraja HS, Davies S, Ewango CEN, Gunatilleke CVS, Nimal Gunatilleke IAU, Hubbell S, Kenfack D, Kiratiprayoon S, Lin Y, Makana J-R, Pongpattananurak N, Pulla S, Punchi-Manage R, Sukumar R, Su S-H, Sun I-F, Suresh HS, Tan S, Thomas D, Yap S (2014) Temporal variability of forest communities: empirical estimates of population change in 4000 tree species. Ecol Lett 17:855-865

Clark DA, Clark DB (1994) Climate-induced annual variation in canopy tree growth in a Costa Rican tropical rain forest. J Ecol 82:865-872

Condit R (1998a) Ecological implications of changes in drought patterns: shifts in forest composition in Panama. Clim Chang 39:413-427
Condit R (1998b) Tropical Forest Census Plots: Methods and Results from Barro Colorado Island, Panama and a Comparison with Other Plots. Springer-Verlag, Berlin

Condit R, Aguilar S, Hernandez R, Pérez R, Lao S, Angehr G, Hubbell S, Foster R (2004) Tropical forest dynamics across a rainfall gradient and the impact of an El Niño dry season. J Trop Ecol 20:51-72

Condit R, Ashton P, Bunyavejchewin S, Dattaraja HS, Davies S, Esufali S, Ewango C, Foster R, Gunatilleke IAUN, Gunatilleke CVS, Hall P, Harms KE, Hart T, Hernandez C, Hubbell S, Itoh A, Kiratiprayoon S, Lafrankie J, de Lao SL, Makana J-R, Noor MNS, Kassim AR, Russo S, Sukumar R, Samper C, Suresh HS, Tan S, Thomas S, Valencia R, Vallejo M, Villa G, Zillio T (2006) The importance of demographic niches to tree diversity. Science 313:98-101

Condit R, Ashton P, Manokaran N, LaFrankie J, Hubbell S, Foster R (1999) Dynamics of the forest communities at Pasoh and Barro Colorado: comparing two 50-ha plots. Philos Trans R Soc B Biol Sci 354:1739-1748

Condit R, Chisholm RA, Hubbell SP (2012) Thirty years of forest census at Barro Colorado and the importance of immigration in maintaining diversity. PLoS ONE 7:e49826

Condit R, Hubbell SP, Foster RB (1992a) Recruitment near conspecific adults and the maintenance of tree and shrub diversity in a neotropical forest. Am Nat 140:261

Condit R, Hubbell SP, Foster RB (1992b) Short-term dynamics of a neotropical forest. Bioscience 42:822-828

Condit R, Hubbell SP, Foster RB (1993a) Identifying fast-growing native trees from the Neotropics using data from a large, permanent census plot. For Ecol Manag 62:123-143

Condit R, Hubbell SP, Foster RB (1993b) Mortality and growth of a commercial hardwood, "El Cativo", Prioria copaifera. Forest Ecol Manag 62:107-122

Condit R, Hubbell SP, Foster RB (1995) Mortality rates of 205 Neotropical tree and shrub species and the impact of a severe drought. Ecol Monogr 65:419-429

Condit R, Hubbell SP, Foster RB (1996a) Assessing the response of plant functional types to climatic change in tropical forests. J Veg Sci 7:405-416

Condit R, Hubbell SP, Foster RB (1996b) Changes in tree species abundance in a Neotropical forest: impact of climate change. J Trop Ecol 12:231-256

Condit R, Hubbell SP, Lafrankie JV, Sukumar R, Manokaran N, Foster RB, Ashton PS (1996c) Species-area and species-individual relationships for tropical trees: a comparison of three 50-ha plots. J Ecol 84:549-562

Couralet C, Sterck FJ, Sass-Klaassen U, Van Acker J, Beeckman H (2010) Species-Specific Growth Responses to Climate Variations in Understory Trees of a Central African Rain Forest. Biotropica 42:503-511

De Cauwer V, Geldenhuys CJ, Aerts R, Kabajani M, Muys B (2016) Patterns of forest composition and their long term environmental drivers in the tropical dry forest transition zone of southern Africa. For Ecosyst 3:23

Devall MS, Parresol BR, Wright SJ (1995) Dendroecological analysis of Cordia alliodora, Pseudobombax septenatum, and Annona spraguei in Central Panama. IAWA J 16:411-424

Engelbrecht BMJ, Comita LS, Condit R, Kursar TA, Tyree MT, Turner BL, Hubbell SP (2007) Drought sensitivity shapes species distribution patterns in tropical forests. Nature 447:80-82

Enquist BJ, Enquist CA (2011) Long-term change within a Neotropical forest: assessing differential functional and floristic responses to disturbance and drought. Glob Chang Biol 17:1408-1424

Enquist BJ, Leffler AJ (2001) Long-term tree ring chronologies from sympatric tropical dry-forest trees: individualistic responses to climatic variation. J Trop Ecol 17:41-60

Gelman A, Hill J (2007) Data Analysis Using Regression and Multilevel-Hierarchical Models. Cambridge University Press, Cambridge

Greenwood S, Ruiz-Benito P, Martínez-Vilalta J, Lloret F, Kitzberger T, Allen CD, Fensham R, Laughlin DC, Kattge J, Bönisch G (2017) Tree mortality across biomes is promoted by drought intensity, lower wood density and higher specific leaf area. Ecol Lett 20:539-553

Hacket-Pain AJ, Friend AD, Lageard JG, Thomas PA (2015) The influence of masting phenomenon on growth-climate relationships in trees: explaining the influence of previous summers' climate on ring width. Tree Physiol 35:319-330

Harms K, Condit R, Hubbell S, Foster R (2001) Habitat associations of trees and shrubs in a 50-ha Neotropical forest plot. J Ecol 89:947-959

Hubbell SP, Foster RB (1983) Diversity of canopy trees in a neotropical forest and implications for conservation. In: Whitmore T, Chadwick A, Sutton A 
(eds). Tropical Rain Forest: Ecology and Management. The British Ecological Society, Oxford. pp 25-41

Hubbell SP, Foster RB (1990) Structure, dynamics, and equilibrium status of old-growth forest on Barro Colorado Island. Four Neotropical Rain Forests. pp. 522-541

Hubbell SP, Foster RB (1992) Short-term population dynamics of a neotropical forest: why ecological research matters to tropical conservation and management. Oikos 63:48-61

John JA, Draper NR (1980) An Alternative Family of Transformations. J R Stat Soc: Ser C: Appl Stat 29:190-197

Kenfack D, Chuyong G, Condit R, Russo S, Thomas D (2014) Demographic variation and habitat specialization of tree species in a diverse tropical forest of Cameroon. For Ecosyst 1:1-13

Leigh EGJ, Windsor DM, Rand AS, Foster RB (1990) The impact of the "El Niño" drought of 1982-83 on a Panamanian semideciduous forest. Glob Ecol Consequences 1982-83 El Niño-South Oscillation 52:473-486

Lewis S, Phillips O, Baker T, Lloyd J, Malhi Y, Almeida S, Higuchi N, Laurance W, Neill D, Silva J, Terborgh J, Lezama A, Martinez R, Brown S, Chave J, Kuebler C, Vargas P, Vinceti B (2004) Concerted changes in tropical forest structure and dynamics: evidence from 50 South American long-term plots. Philos Trans R Soc Lond B Biol Sci 359:421-436

McGee VE, Carleton WT (1970) Piecewise Regression. J Am Stat Assoc 65:1109-1124

Nakagawa M, Tanaka K, Nakashizuka T, Ohkubo T, Kato T, Maeda T, Sato K, Miguchi H, Nagamasu H, Ogino K, Teo S, Hamid AA, Lee HS (2000) Impact of severe drought associated with the 1997-1998 El Niño in a tropical forest in Sarawak. J Trop Ecol 16:355-367

Nath CD, Dattaraja HS, Suresh HS, Joshi NV, Sukumar R (2006) Patterns of tree growth in relation to environmental variability in the tropical dry deciduous forest at Mudumalai, southern India. J Biosci 31:651-669

Newbery DM, Lingenfelder M (2009) Plurality of Tree Species Responses to Drought Perturbation in Bornean Tropical Rain Forest. Plant Ecol 201:147-167

O'Brien MJ, Engelbrecht BMJ, Joswig J, Pereyra G, Schuldt B, Jansen S, Kattge J, Landhäusser SM, Levick SR, Preisler Y, Väänänen P, Macinnis-Ng C (2017) A synthesis of tree functional traits related to drought-induced mortality in forests across climatic zones. J Appl Ecol 1-18. doi:10.1111/1365-2664. 12874

Phillips OL, Van Der Heijden G, Lewis SL, López-Gonález G, Aragão LEOC, Lloyd J, Malhi Y, Monteagudo A, Almeida S, Dávila EA, Amaral I, Andelman S, Andrade A, Arroyo L, Aymard G, Baker TR, Blanc L, Bonal D, De Oliveira İCA, Chao K-J, Cardozo ND, Da Costa L, Feldpausch TR, Fisher JB, Fyllas N, Freitas M, Galbraith D, Gloor E, Higuchi N, Honorio E, Jiménez E, Keeling H, Killeen TJ, Lovett J, Meir P, Mendoza C, Morel A, Vargas PN, Patiño S, Peh KS-H, Cruz AP, Prieto A, Quesada CA, Ramírez F, Ramírez H, Rudas A, Salamão R, Schwarz M, Silva J, Silveira M, Ferry Slik J, Sonké B, Thomas AS, Stropp J, Taplin JRD, Vásquez R, Vilanova E (2010) Drought-mortality relationships for tropical forests. New Phytol 187:631-646

Rüger N, Berger U, Hubbell SP, Vieilledent G, Condit R (2011a) Growth Strategies of Tropical Tree Species: Disentangling Light and Size Effects. PLOS ONE 6:e:25330

Rüger N, Huth A, Hubbell SP, Condit R (2009) Response of recruitment to light availability across a tropical lowland rain forest community. J Ecol 97:1360

Rüger N, Huth A, Hubbell SP, Condit R (2011b) Determinants of mortality across a tropical lowland rainforest community. Oikos 120:1047-1056

Seydack AH, Durrheim G, Louw JH (2011) Spatiotemporally interactive growth dynamics in selected South African forests: Edaphoclimatic environment, crowding and climate effects. For Ecol Manag 261:1152-1169

Tukey JW (1957) On the Comparative Anatomy of Transformations. Ann Math Stat 28:602-632

van der Maaten-Theunissen M, Bümmerstede H, Iwanowski J, Scharnweber T, Wilmking M, van der Maaten E (2016) Drought sensitivity of beech on a shallow chalk soil in northeastern Germany - a comparative study. For Ecosyst 3:24-24

Williamson GB, Laurance WF, Oliveira AA, Delamonica P, Gascon C, Lovejoy TE (2000) Amazonian tree mortality during the 1997 El Nino drought. Conserv Biol 14:1538-1542

Wright SJ, Carrasco C, Calderon O, Paton S (1999) The El Niño Southern Oscillation, variable fruit production, and famine in a tropical forest. Ecology 80:1632-1647

\section{Submit your manuscript to a SpringerOpen ${ }^{\circ}$ journal and benefit from:}

- Convenient online submission

- Rigorous peer review

- Open access: articles freely available online

- High visibility within the field

- Retaining the copyright to your article

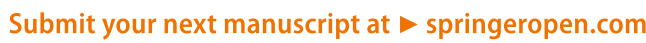

